\title{
The Need for a Model to Facilitate Health for Pregnant Learners Attending Secondary Schools in South Africa
}

\author{
Mr Sogo F Matlala \\ University of South Africa \\ matlalasf@gmail.com
}

Prof AGW Nolte

University of South Africa agwnolte@uj.ac.za

Dr MA Temane

University of South Africa anniet@uj.ac.za

Doi:10.5901/mjss.2014.v5n25p83

\begin{abstract}
The aim of this paper is to point out the need for a model to facilitate health for pregnant learners attending secondary schools in South Africa. It motivates this need by presenting the findings of a study on the exploration and description of the experiences of pregnant learners attending secondary schools in Limpopo province of South Africa.A qualitative, exploratory, descriptive and contextual design was used to explore experiences of pregnant learners who attended secondary schools in Limpopo province. Semi-structured interviews were conducted with learners who were pregnant or were at some stage pregnant while attending secondary schools. A purposive sampling was used to select participants and due to data saturation ten learners participated. Data analysis generated six themes and eleven categories. The themes are (1) identification of pregnant learners, (2) continuation of pregnant learners' school career, (3) dilemmas related to school-attending pregnant learners, (4) support of school-attending pregnant learners, (5) gender in pregnancy caretaking and (6) communication and cooperation between teachers and parents. Pregnant learners revealed themselves while others were identified by their parents and teachers as they attempted to hide their pregnancies. Some pregnant learners continued attending school even when they faced challenges while others dropped out. Pregnant learnersreceived support from teachers and parentsbut in some cases that vital cooperation between parents and teachers was lacking. It can be concluded that pregnant learners facedhealth related challenges to continue attending school which requires a health facilitation model to enable pregnant learners to benefit from schooling and have positive health outcomes.
\end{abstract}

Keywords: learner pregnancy, school health services, teacher-parent communication, learner support, teenage pregnancy

\section{Introduction}

There is an increased visibility of pregnant learners at secondary schools in South Africa these days and most of them are still teenagers (James, van Rooyen andvan Der Strumpher, 2011; Runhare andVandeyar, 2011; Maholo, Maja and Wright, 2009; Panday, Makiwane, Ranchod and Letsoalo, 2009). Teenage pregnancy is a public health concern (Chanjar, Chommanard and Lookid, 2009; Richter andMlambo, 2005) as most teenage pregnancies fall in the category of high risk pregnancies which require appropriate care during the antenatal, labour and postnatal periods to ensure good health for the mother and child (Nolte, 2011; Restrepo-Méndez, Barros, Santos, Menezes,Matijasevich,Barros and Victoria, 2011; Ehlers, 2010; James, van Rooyen and Strumpher, 2010; Kanku and Mash, 2010). According to Chopra, Daviaud, Pattinson, Fonn and Lawn (2009), regular antenatal visits and improved referral links between the home and the health facility are required to reduce child mortality and improve maternal health in South Africa.

Compared to other provinces in South Africa, Limpopo had the highest number of pregnant learners in 2011 (Department of Basic Education, 2012; Department of Basic Education, 2011). Newspapers, which Oosthuizen (2012) and Daku, Gibbs and Heyman (2012) regard as important sources of knowledge for the general public and policy makers, reported frequently about pregnant learners in all nine provinces of the country (The Mercury 2012:14; Cape Times 
2012:1; The Mail and Guardian 2012:23). Unlike in the past when pregnant learners were expelled from schools, these days the Department of Basic Education encourages them to continue attending and forbids school governing bodies from expelling these learners so that they are not further disadvantaged by lack of education (Department of Education, 2007; Bhana, Morrell, Shefer and Ngabaza, 2010). This then leads to a disturbing presence of pregnant learners at secondary school premises as secondary schools cannot adequately provide for their health needs. Mohlabi, Van Aswagen and Mokwena (2010) point out that school health services programme in South Africa is facing many challenges and has collapsed in many provinces leaving schools without the ability to provide even the basic health services to learners.

There are also numerous reported cases of pregnant learners that gave birth at secondary school premises while others gave birth before they reached a health facility (Sunday Times, 2009; Independent online, 2009; The Mail \& Guardian online, 2011). Some of those learners gave birth alone while others were assisted by teachers who were not skilled birth attendants and in the process those pregnant learners were exposed to unhygienic conditions and practices which could affect the mother and the child's health negatively (McLelland, McKenna and Archer, 2012; Save the Children, 2011; MpanzaandNzima, 2010). Some teachers in South Africa perceive pregnant learners as disturbance to the learning and teaching environment of a school while others have a negative attitude towards them and even ill-treat them until they drop out of school (Bhana et al., 2010; Mpanza and Nzima, 2010). Learners in secondary schools are in their teenage years and pregnancy in most teenagers poses some risks to the lives of the pregnant teenager and that of the unborn child (James et al., 2011; Bopape, Mbhenyane and Alberts, 2008; Flair, 2008; Guffey, 2008, United Nations Children's Fund, 2008).

\section{Research Design and Method}

The study used qualitative method which was exploratory, descriptive and contextual.Liamputtong (2013) points out that qualitative method is "a suitable method to understanding the meanings, interpretations and subjective experiences of participants" who in this study were pregnant learners.In an exploratory design the researcher investigates the full nature of a phenomenon in order to understand its manifestations and underlying processes (Polit and Beck, 2012) while in a descriptive design, the researcher describes what he or she has observed in order to provide deeper meaning of the experiences of participants (Rubin and Babbie, 2013). The design for this study was exploratory and descriptive as the experiences of pregnant learners onhow they were supported to meet their health and educational needs were explored and then described. Creswell (2013) points out that a study is contextual when a researcher collects data from participants at the natural site where they experience the phenomenon rather than in a laboratory. In this study, the researchers interviewed pregnant learnersat their schools and that enabled the researchers to observe the environment where pregnant learners experienced health and educational support.

\subsection{Study Population and Sampling}

The population in this study consisted of pregnant learners and other learners who were pregnant at some point while attending secondary schools.A sample is a small part of the population that the researcher selects to participate in the study and represents the entire population (Polit and Beck 2012). According to Liamputtong (2013) and Streubert and Carpenter (2011), sampling in qualitative research is done for the purpose of getting meaning of what participants give to their experiences rather than for the frequency of what participants say and therefore the findings cannot be generalised to the entire population.In this study a purposive sampling strategy was used to access the population of pregnant learnersfrom secondary schools in Limpopo Province. In purposive sampling strategy, the researcher purposefully selects specific participants because of their first-hand experience with the topic of the study or their perceived ability to provide information relevant to the purpose of the study (Streubert and Carpenter, 2011; Liamputtong, 2013; May, 2011). Liamputtong (2013) and StreubertandCarpenter (2011) refer to these specific participants from whom the researcher can learn a great deal about important issues central to the purpose of the research, as information-rich cases. The criteria for the selection of information-rich cases were:

- Learner should be between the ages of 13 and 19 years.

- The learner should be pregnant during period of research study or should have given birth whilst in secondary school.

- Willingness to participate in sharing her experiences of being pregnant in a secondary school.

- Have a signed consent form from parent or guardian to participate in the study. 
The sample size was determined by saturation of data which resulted in 10 learners participating in the study. Streubert and Carpenter (2011:30) define saturation of data as "the repetition of discovered information and confirmation of previously confirmed data".

\subsection{Data Collection}

The researchers chose semi- structured interview as the most appropriate strategy to collect data. A semi-structured interview is a flexible type of interview where the researcher specifies questions to be asked in advance but is free to ask them in any order to respond to the way the participant has answered the initial question (Polit and Beck, 2012). The researcher can ask the participant to clarify and elaborate on some of the answers given, and as May (2013:134) puts it "enter into a dialogue with the interviewee". In this dialogue participants are free to articulate their worldviews while at the same time the researcher is able to focus on the research topic (Liamputtong, 2013). Participants are also free to decide on the type, length and amount of answers they provide to each question (May, 2011; Packer 2011 and Streubert and Carpenter, 2011). May (2011) further indicates that a semi-structured interview represents an opening up to an understanding of how participants produce and deploy meaning in social life when they answer questions that the researcher did not ask but which are meaningful to participants' lives.

The researchers considered semi-structure interview as the one strategy that would cause minimal disturbance to the education programme of the schools as learners were interviewed individually as they became available for the interview between lessons. The fact that learner pregnancy is a sensitive topic also influenced the researchers to select the semi-structured interview strategy.

The two broad questions that researchers asked learners in the interviews were:

- Tell me about your experience of being pregnant while attending a secondary school.

- What do you think can be done to support or assist pregnant learners in secondary schools to stay healthy and make good progress with school work?

The semi-structured interviews lasted between 30 and 35 minutes each and were audio-taped. The researcher also collected field notes which are, according to Politand Beck (2012)a record of unstructured observations the researcher made while collecting data as well as their interpretation. The field notes kept provided contextual information about time and place of interviews and further served as data for analysis.

\subsection{Ethical Considerations}

The ethical principles in this study were guided by the principles of respect for persons, beneficence and justice. To maintain scientific integrity, the researchers obtained ethical clearance from the Department of Health Studies at The University of South Africa (UNISA). After ethical clearance was given, the researchers then applied to the Limpopo Department of Education to get permission to collect data from secondary schools. Once permission was given, the researchers approached the circuit offices of education in order to get permission to visit identified schools to collect data. At the identified schools, the researchers requested and obtained informed consent from the learners to participate in the study voluntarily.As suggested by Strode, Slack and Essack(2010) and Strode and Slack (2011),the researchers requested the parents of the learners to give written consent for the learners to participateas learners were not legally competent to give consent on their own.

The right to privacy for participants was maintained throughout the study by asking only questions relevant to the aim and objectives of the study. Polit and Beck (2012) indicate that researchers should ensure that their research is not more intrusive than it needs to be and that the participants' privacy is maintained throughout the study. To further ensure privacy, the researchers informed participants not to mention their names, their schools' names and the names of any other person during the interviews so that data cannot be linked to the identities of participants in any way as suggested by de Vos, Fouche and Delport (2011).

\subsection{Trustworthiness of the Study}

Credibility, dependability, transferability and confirmability were used as strategies to ensure trustworthiness of qualitative studies as suggested by Politand Beck (2012) and de Vos, Strydom, Fouche andDelport (2011). 


\section{Data Analysis and Interpretation}

Data analysis is a process of examining and interpreting data in order to get meaning and gain understanding,and in qualitative research, the processcommencesduring data collection (Grove, Burns and Gray, 2013).The researchers transcribed all interview recordings verbatim as part of data analysis. The process of transcribing recordings gave the researchers an opportunity to immerse themselves in the data and that became important for analysis. The researchers used Tesch's open coding process described in Creswell (2003) to code the transcripts. For verification,transcripts were then sent to an independent coder and the results were compared with the codes made by the researchers. The researchers and the independent coder met to reach an agreement on the codes.

\section{Research Findings and Discussion}

Six themes emerged from data analysis and are listed and discussed below.

\subsection{Identification of pregnant learners}

This theme explored how teachers, parents and other learners became aware that a particular learner in their school was pregnant. It further explored how they reacted after they became aware that a particular learner was pregnant.

Some pregnant learners told their parents and teachers about their pregnancies while others chose to be secretive about it.One learner approached her class teacher and told her that she was pregnant as shown by this quote: "I told my class teacher before she could see me". One pregnant learner informed her parents about her pregnancy and the parents made the principal aware of pregnancy but he tried to hide it to other teachers and learners in the school as shown by this quote from a learner: "...firstly I told my mom at home and then I asked her to ask the principal if I can come to school and the principal agreed, but he said if I come to school I must always wear a blazer so that the stomach does not show and people cannot not see"

Some pregnant learners accepted that they were pregnant but attempted to hide it from their parents and teachers as shown by this quote: "I knew after two months that I was pregnant and I didn't want to tell her but by the look of her eyes I could see that she already knew but she didn't want to tell me or she wanted me to tell her first". Another said: "I got pregnant on October and my parent found out on February the following year. My mother found out in February and my teacher in April. I remember it was on the 16th"

Teenage pregnancy, according to James, van Rooyen and Strumpher (2012) is perceived as morally wrong, a disgrace and a stigma in some communities in South Africa. Pregnant learners, their parents and teachers get embarrassed and feel sad when they identified that a learner is pregnant, thus they attempt to hide pregnancy from other learners, educators and parents. Ngabaza and Shefer (2013) indicate that some schools are intolerant to pregnant learners thus the reluctance of pregnant learners to disclose. Mpanza and Nzima (2010) also found that pregnant learners do not disclose their pregnancies to their parents and to teachers and this makes it difficult for parents and teachers to provide support. Learners who are open about their pregnancies benefit by accessing support from parents, teachers and other learners at school.

One learner indicated that her teacher and parent initially became disappointed when they found out that shewas pregnant but they ultimately accepted it as shown by this quote: "...my parents were also disappointed and I remember my teacher telling me that she didn't...like she didn't even think about me getting pregnant while I was still at school, and I remember my parent, my mother didn't speak to me for a week. She would go to work and when coming back she would come into the house and talk to my sister only, and to my younger sister. She would not greet me and it was the most painful thing because I love my mom. It took time but at the end I was ok, she was ok, she accepted that I am pregnant, there is a baby coming into the house and there is nothing she can do". Another learner said this: "...parents were very, very disappointed, so bitter, so angry, and my mom she didn't want to talk to me, not even look at me. She said I was disgusting and disgusted her. It was, it was very bad, my mom at some point she took me out of the house and told my uncle that I don't want this child anymore and I didn't expect her because she wasn't expecting me to do that but she became ok."

According to Bhana et al.,(2010), some communities in South Africa frame teenage pregnancy as a moral problem; as such it is shamed and punished. Some pregnant learners expressed feelings of shame, embarrassment, humiliation and loosing honour from parents and teachers as these quotes show: "Being pregnant while at school is not a solution, it is nothing; everything, everything just stops, your career, your eh, eh...people won't respect you in the way they used to do because you disappointed them, parents won't look forward toward what they dreamed before because they don't 
trust you anymore". Another said: "it was too embarrassing like eh.... Having that bump...." Another learner was shy as she felt she has disappointed her parents and teachers and this is what she said: "I was very shy, of what people would say, of what my parents would say, of what my teachers would say and I was very disappointed".

\subsection{Continuation of pregnant learners' school career}

This theme discusses how pregnant learners felt about their constitutional right to continue attending school so that they are not disadvantaged by pregnancy. One learner said: "I would say... all pregnant learners should go to school no matter what, no matter what the consequences, they should go to school. Ja (yes) pregnancy is something that wouldn't close your doors to success". Some pregnant learners felt that they should be allowed to attend until some few months before delivery while others felt that attendance should be continued throughout if the learner does not experience serious health problems. This is what one learner said: "I think if you don't have problems you must be allowed because coming to school when you are pregnant is not a bad thing". Another pregnant learner who wanted to continue attending school indicated that it was painful when her parent and her teacher agreed that she should stop attending school due to complications of pregnancy by saying: "And then my mother said I must not come to school anymore and the principal agreed with her, they took my books and I went home, but it was the most painful thing. Every time when I wake up I see girls at my age wearing a school uniforms crossing the road going to school and then here I am with a big tummy, small as I am, so it was not good at all". According to Bhana et al., (2010) some teachers perceive pregnant learners as threats to the way they want to manage learners in classrooms and therefore they do not accept them at school. Ngabaza and Shefer (2013) suggest that parents and teachers should discuss the continuation of schooling of the pregnant learner taking into account the opinion of a doctor, midwife or nurse.

\subsection{Dilemmas related to school-attending pregnant learners}

This theme discusses situations which have two alternatives, each of which has advantages and disadvantages. The Oxford Advanced Learner's Dictionary (2010) defines dilemma as a situation which makes problems, often one in which a person has to make a very difficult choice between things of equal importance. If pregnant learners continue attending school they will complete their schooling, but at the same time it holds health risks for them. If on the other hand they drop out and stay at home the health risks are less but their learning is fragmented. If teachers attend to the pregnant learners' rights to carrying on with schooling, it might end up encouraging or appearing to approve pregnancy among learners, so both options have advantages and disadvantages which make it very difficult to choose what the best thing to do is.

A pregnant learner shared her concerns about something bad happening to the health of pregnant learners and their unborn childrenwhen they continued to attend school this way: "what if something happens while at school? We children we run outside, maybe you find that there is a fight here at school, what if we run on to them and they fall, so I think they have to come to school until 7 months or maybe 6 months because some children ..... 7 months, they have to stay at home". Another added: "when coming to 8 months and half and ja (yes) the last month, I think they should take leave, ja (yes) because, eish anytime complications may happen. When you are at school, nobody would care to help them. So I think being at home would solve everything and make things better".

Some pregnant learners are also concerned about the impact that physical activity of pregnant learners when they play, move between classes and during exercises which are part of their lessons, can have on their health and that of their unborn children. Benelam (2011) indicates that physiological changes occur in the body during pregnancy and these changes cause joint laxity and hypermobility. The author advices that contact sport be avoided and further recommends that exercises in pregnancy be supervised by a health professional. Lewis, Avery, Jennings, Sherwood, Martinson and Crain (2008) indicate that the perception that exercise and physical activities are risky is common amongst people who are not health professionals. A Department of Education in one province of South Africa states that parents of pregnant learners must enter into written agreements with schools their daughters are attending that pregnant learners attend schools at their own risk. These written agreements further indemnify schools against any pregnancy related injuries or accidents that learners may get while at school (Ngabaza and Shafer, 2013).

The role of teachers is to teach but the presence of pregnant learners creates an additional role for teachers and becomes a burden to them. Pregnant learners are aware of the additional burden on their teachers as these quotes show: "The teachers can't teach you and again take you to the hospital, they are always busy; the teachers cannot leave many learners behind in class and look after me alone". Another learner said: "teachers came here to teach us, to give us better education, and we come with eh, eh, burden to them because we... giving birth is not something that you could do 
at a school, that is why I am saying there should not be a person who is pregnant at a school. If now you are going to deliver and the teacher, the female teachers don't know anything about eh, helping a person to deliver a baby, maybe the ambulance is taking too long and the baby is already coming out, you see this is the trouble that we are getting our teachers in". A pregnant learner who is aware of the burden placed on teachers but who wants to continue with schooling said: "when I was so close to giving birth there must be someone close to me who must look after me because the teachers can't do that job because they are busy teaching. So I had to bring my sister to school to look after me until I go home".

\subsection{Support of school-attending pregnant learners}

Pregnant learners who took part in the study indicated that they receivedvarious forms of support from their parents, teachers and other learners so that they could continue to attend school and be healthy.A pregnant learner who enjoyed support from teachers said: "...and then after some several months it became good because my class teacher used to advise me. He said that I must always eat healthy food, exercise and follow my clinic, attendance.., appointments. So I did that. Even the principal was good because at first he was like someone I wasn't used to, wasn't free talking to him.... he advised me, he asked me if the father was around, if he would be able to take care of the baby". Another said: "Sometimes they will call me and talk to me, sometimes, not all the time. My class teacher but sometimes my principal when he had to see me he would ask about my health". A learner expressed support from parents and teachers this way: "I stayed for a week at home because my mother was so supportive; I went to school the following week, I was normal, I was normal and strong. I focussed on the school because of the support from the mother and the teachers".

Other learners at school also play some supportive roles to pregnant learners when invited to do so.A pregnant learner described how another learner helped her this way: "I remember this teacher the other day, it was a male teacher and he didn't know that I was pregnant. I came late to school that day and there was a punishment. They wanted us to do a frog jump, and I couldn't do it, like, this friend of mine, she was my best friend, she quickly came out of the class and then called this sir, teacher and then told him sir l'm sorry to disturb you but my friend can't do frog jump. Sir said why because other children are doing it. That friend of mine told the teacher that because she is pregnant and the teacher said it is ok".

Some teachers and parents supported pregnant learners to access healthcare services outside school premises, as according to Mohlabi, Van Aswagen and Mokwena (2010) school health services have collapsed in many provinces of South Africa. A pregnant learner said this about the support she received from her teacher: "I was always informing my teachers and my principal so that they can give me a free day off so that I can go to the clinic". Another said: "I tell my teacher that I am going to clinic today, let me say I will be going on the 25th September I will talk to her and she allows me, and I will come back the following day. I report back to her and they give me the work that they did".Some learners felt that health professionals and teachers should communicate so as to make it easy for pregnant learners to access healthcare. A learner said: "They should communicate with the hospitals and clinics and tell them at our school we have such a number of pregnant girls and when each one reaches 9 months they must be on standby (ready) so that when we call you can respond immediately. The paramedics, the hospital and the clinics should be alerted".

Some learners felt that their access to health services wouldbe improved if health services were brought to the school rather than them going out. A learner put it this way: "The school must organise a doctor to come see us here at school because, if we, if we are at school we can't see the doctor on Saturday or Sunday because most of them they don't work on weekends. Not all the time but must come and do check-ups so that we can know our status". Another said: "I said they must organise a doctor and a nurse. So nurses and doctors should be here fulltime. The department must sort it out, the school department because they are looking after the children...they must pay them". Another learner who supports the need for on-site health care said: "I think there should be a room with a bed and a first aid kit, maybe with someone with experience there, there should be a person here fulltime who every time he gets out of the house, that person knows where he is going, he is going to a particular high school, being there the whole day waiting for emergencies".

Pregnant learners indicated that they received support from parents and other family members through suggestions from the school. A learner said this about her principal: "He asked them if they could get someone to look after me while I am at school because anytime I could deliver. So my mother referred him to my sister, then my sister came. She sat with me here at school, if I... may have the pains so that she can get help from maybe someone at home because she knows everyone. Because the principal said he cannot eh, attend us all the time..."Another said: "they told me to come with a parent to look after you because when I was so close to giving birth there must be someone close to me who must look after me because the teachers can't do that job because they are busy teaching. So I had to bring my 
sister to school to look after me until I go home. She would sit outside the class so that if there is a problem she must be able to help faster. Next to the class so that when I have a problem they can call her faster to come and assist me. She comes with me in the morning at 7:00 when I come to school and she goes home with me but she came during the time when I was writing (examination), if I was writing at 9:00 she comes and when I bath she would also bath so that she can come with me to school. Another said this as well: "They say if you are 8 months you must come with your parents, because you might give birth here at school. Then they (parents) sit there and when you feel like giving birth then they take you to the hospital because the teachers cannot leave many learners behind in class and look at me alone".

Pregnant learners indicated that teachers treated them differently from other learners but that treatment was in the best interest of the pregnant learners and their unborn children. This is how a learner expressed the treatment she received from her teachers: "Life Orientation, during my life orientation subject, eh... my teacher got to separate me with the other children, so they had to treat me special because they were so scared that maybe I might have an accident while I was practicing". Another expressed it this way: "...sometimes we go for PET, physical exercise and when they exercise I don't do because I can't jump. They won't give me marks, maybe if people go for PET they would give me something to do like drawing or reading an essay and I explain it later in class". Some learners felt they were discriminated against although discrimination was done to their benefits. A learner who felt discriminated against said this: "they were excluding me, maybe they would say when they were doing exercises like jumping and push-ups they would say you no no... Don't do that, you can sit on my chair and watch others; that was not nice, it wasn't good because I would miss participating, I wanted to do that". Another said: "That part, as a learner, when other learners are doing something, you want to take part. Because in PET you relax and learn, it is educational and fun. But the fact that she would allow me to sit there and not take part made me happy because she acknowledge that I am in this state, I can't do this and I can't do that".

\subsection{Gender in pregnancy caretaking}

This theme discusses expectations that pregnant learners had about male and female teachers'involvement in supporting pregnant learners.According to Oxford Advanced Learner's Dictionary (2010) gender refers to the fact of being male or female especially when considered with reference to social and cultural differences, not differences in biology.

Pregnant learners expected female teachers to supportthem as they perceived female teachers to understand what pregnant learners were going through unlike male teachers. This is what a pregnant learner said: "Female teachers because basically they understand it, they understand it more unlike male teachers. Male teachers they do care but not in the way of, not in that way like female teacher is caring". Another said this about her expectations from female teachers: "Even though they are not trained I would say that they have experience in some way because they are the mothers, so...if you are a mother...looking up to a child... nothing is impossible". Another said: "I think schools should have like more supportive systems in terms of female teachers, female teachers...they must always be there. I would suggest that when a girl is pregnant, the girl must go and tell the female teachers and the teachers should know if she is in her first trimester or her second trimester".

Male teachers were not expected to support pregnant learners as this quote from a pregnant learner shows:"I would say it is hard for a male teacher to look up to a pregnant lady because the males are the males and the mothers, you know, the mothers have a lot of experience than the males". Another indicated her discomfort of talking to male teacher while she was pregnant by saying: "I suggest that they should have a separate room for teenage pregnancy, for teenage learners like when they are experiencing something they should be alone in the room accommodated by female teachers as we don't really feel comfortable talking to male teachers".

\subsection{Communication and co-operation between teachers and parents}

This theme discusses interactionsbetween teachers and parents about pregnant learners who continued to attend school.A learner related positive communication and cooperation between her parent and the teacher this way: "And also asked me to bring my parents at school so that he could talk to them. So he then..., I told my parents and they came". Another said: "My mother came here and requested that I should come to school so that they, I could not be deregistered........and then thereafter I continued with schooling". Another learner related it this way: "That female teacher asked for my mother's contacts so that she can call her sometimes and to check upon me, yes, then I gave her...my mother would just call that teacher and I would hear from that teacher that your mother called in the morning and asked did you get to school well. She was communicating, most of the time she was communicating with that teacher". 


\section{Conclusion and Recommendations}

Pregnancy amongst secondary school learners is a challenge to teachers, parents and learners regarding disclosure and support for learners to continue attending school and remaining healthy. A model is therefore required to support pregnant learners when they inform their parents and teachers, to facilitate communication between parents and teachers and to enable pregnant learners to access pregnancy specific health care. The model should take into account gender issues related to support during pregnancy.

The Department of Basic Education, teachers, parents, learners and communities as important stakeholders in the education system, should all work together with the Department of Health to make things easy for pregnant learners to continue attending school and have access to appropriate health services so that they can get education and deliver healthy babies. Working together of these stakeholders will contribute to achievement of Millennium Development Goals for child health, maternal health and access to education.

\section{References}

Bhana, D., Morrell, R., Shefer, T.,\&Ngabaza, S. (2010).South African teachers' responses to teenage pregnancy and teenage mothers in schools. Culture, Health \& Sexuality: An International Journal for Research, Intervention and Care 12(8):871-883

Benelam, B. (2011). Physical activity in pregnancy.Nutrition Bulletin. 36(3):370-372

Bopape, M.M., Mbhenyane, X.G.,\&Alberts, M. (2008).The prevalence of anaemia and selected micronutrient status in pregnant teenagers of Polokwane Municipality in the Limpopo Province. South African Journal of Clinical Nutrition 21(4):332-336

Chanjar, S., Chommanard, W., \&Lookid, C. (2009).Development of a model to prevent premature sexual relations among junior high school female learners in Thailand. Africa Journal of Nursing and Midwifery 11(2):75-84

Chopra,M.,Daviaud,E., Pattinson,R.,Fonn,S., \& Lawn, J.E. (2009). Saving the lives of South Africa's mothers, babiesand children: can the health system deliver? Lancet 374: 835-46

Cape Times. 2012. 1 June:18

Creswell, J.W. (2013). Qualitative inquiry \& research design. Choosing among five approaches, 3rd edition.London:Sage Publications

Creswell, J.W. (2003). Research Design: Qualitative, Quantitative and Mixed methods approach, 2nd edition. London:Sage Publications, Inc

Daku, M., Gibbs, A.,\&Heyman, J. (2012).Representations of MDR and XDR TB in South African newspapers. Social Science \& Medicine 75: $410-418$

Department of Education.(2007). Measures for the Prevention and Management of Learner Pregnancy. Pretoria: Department of Education.

Department of Basic Education.(2012). General household survey 2010: Focus on Schooling. Pretoria: Department of Basic Education

Department of Basic Education.(2011). Report on the 2009/2010 annual survey for ordinary schools. Pretoria: Department of Basic Education.

deVos, A.S., Strydom, H.,Fouche., C.B. \&Delport, C.S.L. (2011) .Research at grass roots for social science and human service profession. 4th edition. Van Schaik: South Africa

Flair, LNL. 2008. High-Risk Pregnancy. Encyclopaedia of Global Health. SAGE Publications 12 May 2011. http://O-www.sageerefference.com.oasis.unisa.ac.za/globalhealth/Article_n580.html>

Grove, S.K., Burns, N., \&Gray, J.R. (2013). The practice of nursing research: Appraisal, synthesis and generation of evidence. 7th edition. Missouri: Elsevier Saunders

Guffey, M.K.(2008).Teenage Pregnancy.Encyclopaedia of Global Health. SAGE Publications 12 May 2011. http://O-www.sageerefference.com.oasis.unisa.ac.za/globalhealth/Article_n1153.html>

Independent On Line 2009. 24 August

James,S., van Rooyen, D.,\& van Der Strümpher, J. (2010). A model for the facilitation of intergenerational reconciliation in teenage pregnancy: a Xhosa perspective. Africa Journal of Nursing and Midwifery 12 (2):3-13

James, S., van Rooyen, D.,\& van Der Strümpher, J. (2011). Experiences of teenage pregnancy among Xhosa families. Midwifery 28:190-197

Kanku, T., \& Mash, R. (2010). Attitudes, perceptions and understanding amongst teenagers regarding teenage pregnancy, sexuality and contraception in Taung. South African Family Practice 52(6):563-572

Lewis,B., Avery, M., Jennings, E., Sherwood, N., Martinson, B., \& Crain L. (2008). The effect of exercise during pregnancy on maternal outcomes: Practical implications for practice. American Journal of Lifestyle Medicine. 2(5):441-455

Liamputtong, P. (2013). Qualitative research methods. Victoria: Oxford University Press

Maholo, R.B., Maja, T.M.,\&Wright, S.C.D. (2009). Relationships, perceptions and the socio-cultural environment of pregnant teenagers. Africa Journal of Nursing and Midwifery 11(2):46-58

May, T. (2011). Social research: issues, methods and process, 4th edition. New York: Open University Press

McLelland, G., McKenna, L., \& Archer, F. (2013.) No fixed place of birth: Unplanned BBAs in Victoria, Australia. Midwifery 29:e19-e25

Mohlabi, D.R.,VanAswegen, E.J.,\&Mokwena, J.D. (2010). Barriers to the successful implementation of school health services in the Mpumalanga and Gauteng provinces. South African Family Practice 52 (3): 249-254. 
Mpanza, N.D \&Nzima D.R. (2010).Attitudes of educators towards teenage pregnancy.Procedia Social and Behavioral Sciences 5: 431439

Nolte, A.G.W(ed). (2011). A textbook for midwives. Pretoria: van Schaik Publishers

Ngabaza, S., \& Shefer, T. (2013).Policy commitments vs. lived realities of young pregnant womenand mothers in school, Western Cape, South Africa.Reproductive Health Matters.21(41):106-113

Oosthuizen, M.J. (2012). The portrayal of nursing in South African newspapers: A qualitative content analysis. African Journal of Nursing and Midwifery 14 (1): 49-62

Oxford Advanced Learner's Dictionary.(2010). 2nd edition. Oxford: Clarendon Press.

Packer, M. (2011). The science of qualitative research. New York: Cambridge University Press

Panday, S., Makiwane, M., Ranchod, C., \& Letsoalo, T. (2009).Teenage pregnancy in South Africa - with a specific focus on schoolgoing learners. Human Sciences Research Council. Pretoria: Department of Basic Education.

Polit, D.F., \& Beck, C.T. (2012) Nursing Research. Generating and assessing evidence for nursing practice. 9th edition. Philadelphia: Lippincott Williams and Williams

Restrepo-Méndez, M.C., Barros,A.J.D., Santos, I.S., Menezes, A.M.B., Matijasevich, A., Barros, F.C., \&Victora, C.G. (2011). Childbearing during adolescence and offspring mortality: findings from three population-based cohorts in southern Brazil. BMC Public Health 11:781-804

Richter, M.S., \&Mlambo, G.T. (2005).Perceptions of rural teenagers on teenage pregnancy. Health SA Gesondheid 10(2):61-69

Rubin,A.,\&Babbie, E. (2013).Essential research methods for social work.3rd edition. Asia: Brooks/Cole, Cengage Learning

Runhare, T., \&Vandeyar, S. (2011). Loss of learning space within a legally inclusive education system: institutional responsiveness to mainstreaming of pregnant learners in formal education. Gender and Behaviour 9 (2):4100-4124

Save the Children. (2011). Missing Midwives. London: Save the Children UK.

Streubert,H.J., Carpenter, D.R. (2011). Qualitative research in nursing: advancing the humanistic imperative; 5th edition. Tokyo: Lippincott Williams \& Wilkins

Strode, A., Slack, C.,\&Essack, Z. (2010).Child consent in South African law: Implications for researchers, service providers and policymakers. South African Medical Journal 100(4):247-250

Strode, A.,\& Slack, C. (2011).Using the concept of 'parental responsibilities and rights' to identify adults able to provide proxy consent to child research in South Africa. South African Journal of Bioethics and Law, 3(2), 55-58.

Sunday Times. 2009. 28 August 53

The Mail \& Guardian online. 2011.18 February 34.

The Mail and Guardian. 2012. 23 May 18.

The Mercury. 2012. 14 June: 6

United Nations Children's Fund, (2008). The State of the World's Children 2009. New York: UNICEF 